\title{
İ̧ Sağlığı ve Güvenliği Kapsamında Nanomateryal Risk Değerlendirmesi
}

\author{
Nanomaterial Risk Assesment Review \\ in the Scope of Occupational Health and Safety
}

\author{
Ibrahim EYi
}

\begin{abstract}
ÖZET
Mühendislik ürünü olan Nanomatereyaller(Nm)'in sağlığa yönelik tehlikeleri konusunda artan bir endișe bulunmaktadır. Bu durum risk grubu altında olan çalışanların Nm’lere maruziyetinin oluşabileceği alanlar ile ilgili mevcut tehlikelerin, risk faktörlerinin tanımlanması, risk değerlendirme methotlarının geliştirilmesi konularında çalışmalara gereksinim olduğunu ortaya çıkarmaktadır. Nanomateryal proseslerle ilgili belirlenmiş bazı standartlar ve sektörel bazda gelişmeler olsada sistematik çerçeve tam anlamıyla oluşmamıştır. Gelişen teknoloji ile kendisine her geçen gün daha fazla kullanım alanı bulan nanomateryallerin gelecekte insan sağlığına ne gibi zararlar verebileceği araştırılması gereken diğer bir konudur. Bu çalışmada iş sağlığı ve güvenliğinde kapsamında nanomateryallerin özellikleri, risk faktörleri ile nanomateryallerde risk yönetiminde izlenecek risk analiz methodları konusunda perspektif sunabilmek amaçlanmıştır.
\end{abstract}

Anahtar Kelimeler: Nanoteknoloji, Nanomateryal, Nanopartikül, İș Sağlığı ve Güvenliği, Risk Yönetimi, Risk Değerlendirmesi, Risk Analizi

\begin{abstract}
Nanomaterials is engineered materials and there is a growing concern of harmful effects for human health. These concerns have been directed to identify threats, determine risk factors, improve risk assessment methods for occupational health and safety in areas where worker exposure exists. Although there are improvements in sectoral base for nanomaterials and its processes, there isn't complete regulation or systematic framework containing all risks. It is also not clear how nanomaterials will affect worker's health in the future. The purpose of this study is to define consize information about risk factors, risk assessments, analysis methods and give a perspective of nanomaterials in context of occupational health and safety.
\end{abstract}

Keywords: Nanotechnology, Nanomaterial, Nanoparticle, Occupational Health and Safety, Risk Management, Risk Assessment, Risk Analysis

İbrahim EYi - İstanbul Aydın Üniversitesi, Fen Bilimleri Enstitüsü, İş Sağlığı ve Güvenliği Doktora Öğr. İstanbul, Türkiye Ibrahim EYI, PhD Student - Istanbul Aydın University Institute of Science and Technology, Occupational Health and Safety Istanbul, Turkey ibrahimey@yahoo.com

Received/Geliş Tarihi : 31.08.2018 Accepted/Kabul Tarihi: 31.12.2018 


\section{GİRIŞ}

Nano Yunanca anlamına gelen bir kelimeden türetilmiş olan bir ön ektir. ABD Milli Nanoteknoloji Kurumu nanoölçekli materyalleri; boyutları 1-100 nanometre (nm) aralığında olan, mühendislik yöntemleri ile boyutlarına has özelliklerde üretilmiş malzemeler olarak tanımlamaktadır $[1,2]$. Nanomateryaller nano-boyutlariyla karakterize edilmekle beraber özellikleri aynı materyalin daha büyük parçacıklı halinden büyük ölçüde farklılık göstermektedir. Bu farklılıklar nanomateryalleri tıp, çevre ve enerji gibi alanlarda yeni ve gelişmiş aplikasyonlar için uygun hale getirmektedir [3]. Nanomateryal malzemeler bu özellikleri ile belirli bir amaç olmadan doğal yollarla oluşan ve aynı ölçeğe sahip olabilen ultra-ince partiküllü malzemeler ile farklılık göstermektedir. Ultra-ince terimi İş ve Çevre Sağlığı alanında çap olarak 100 nm'den daha küçük uçucu partikülleri tanımlamak için kullanılmaktadır. Ultra-ince partiküller kasıtlı olarak üretilmemekte ancak kaynak, eritme, yakıt yanması, ateş vb gibi yanma ve buharlaşma proseslerinin birer ürünleri olarak ortaya çıkmaktadır [1].

Mühendislik Nanomateryalleri (MNm) alanındaki teknolojinin gelişimi, bu teknolojinin sağlık ve çevreye olan etkileri ile ilgili bazı endişeleride beraberinde getirmektedir $[1,4]$. Mühendislik Nanomateryallerinin (MNm) inflamasyon, astım alevlenmesi, genotoksisite ve solunum yolu kanserleri gibi ultra-ince partiküllerin insan sağlığında neden olduğu tehditlere benzer zararlara neden olabileceği de söylenmektedir.

\section{MÜHENDİSLİK NANOMATERYALLERİNIIN GENEL KARAKTERISTTIKLERİ}

Genellikle karbon yada metal/metal oksit bileşimleridir. Karbon bazlı MNm’leri tek duvarlı ve çok duvarlı karbon nanotüpleri, grafen (hegzagonal yapıda tek tabakalı karbon yapı), küresel fullerenler (üç-koordinatlı karbon atomlarını içeren 20-80 karbon atomlarından oluşan kapalı kafes yapıları), C60 (Buckyballs, buckminsterfullerene) ve simetrik olan dendrimenleri içermektedir. MNm’lerin üretim sonucunda elde edilen kimyasal özellikleri nanomateryallere çeşitli kullanım özellikleri (Tablo 1) ve avantajları kazandirmaktadır [23].

Boyut farklılıkları açısından tek duvarlı karbon nanotüpler ve çok duvarlı karbon nanotüpler $1-2$ ve $2-50 \mathrm{~nm}$

Tablo 1: Nanomateryallerin kimyasal özelliklerine göre kullanımı [23]

\begin{tabular}{|c|c|c|c|}
\hline Nanomateryal Türü & Örnekleri & Kimyasal Özellikleri & Uygulama \\
\hline Karbon NM'leri & $\begin{array}{l}\text { Fullerenler, Buckyball, }\left(\mathrm{C}_{60}, \mathrm{C}_{20}, \mathrm{C}_{70}\right) \text {, } \\
\text { karbonnaotüpler, nanoelmaslar, } \\
\text { nanoteller }\end{array}$ & $\begin{array}{l}\text { Stabil, sınırlı reaktivite, yüksek } \\
\text { antioksidan }\end{array}$ & $\begin{array}{l}\text { Biyomedikal, süperkondensatörler, } \\
\text { sensörler, fotovoltaik }\end{array}$ \\
\hline Metal oksitler & $\mathrm{TiO}_{2}, \mathrm{ZnO}, \mathrm{CeO}_{2}$ & Yüksek reaktivite, fotovoltaik özellikler & $\begin{array}{l}\text { Fotokatalist, pigmentler, ilaç iletimi, } \\
\text { teşhis, UV koruyucu, dizel yakıt katkısı }\end{array}$ \\
\hline Zero-valent Malzeme & nZVI, EZVI, BNPs & Yüksek yüzey aktivitesi & $\begin{array}{l}\text { Kirleticilerin (nitrat gibi) azaltılmasın- } \\
\text { da kullanım }\end{array}$ \\
\hline Quantum Dot'lar & CdSe, CdTe ve $\mathrm{ZnSe}$ & Paket yariiletkenlik & $\begin{array}{l}\text { Medikal teşhis,fotovoltaik, } \\
\text { telekominikasyon, sensörler }\end{array}$ \\
\hline Dendrimenler & $\begin{array}{l}\text { Hiper polimerler, dendrigaft } \\
\text { polimerler ve dendron }\end{array}$ & Multifonksiyonel polimerler & $\begin{array}{l}\text { İlaç iletimi, kimyasal sensörler, } \\
\text { medifiye elektrotlar, DNA taşıyıcılar }\end{array}$ \\
\hline Kompozit Nm'ler & $\begin{array}{l}\text { Sentetik polimerle ve reçinelerle, } \\
\text { Nanokillerle ve diğer Nm'ler ile } \\
\text { birleşmiş }\end{array}$ & $\begin{array}{l}\text { Multifonksiyonel komponentler, } \\
\text { katalitik özellikler }\end{array}$ & $\begin{array}{l}\text { Mekanik ve alev geciktirici özellikler, } \\
\text { ilaç iletimi }\end{array}$ \\
\hline Gümüş Nm'ler & $\begin{array}{l}\text { Kolloid Gümüş, gümüş teller, nano- } \\
\text { gümüş toz ve polimerik gümüş }\end{array}$ & $\begin{array}{l}\text { Yüksek yüzey reaktivitesi, antimikrobi- } \\
\text { yal özellikler }\end{array}$ & $\begin{array}{l}\text { Medical uygulamalar, su saflaştırması, } \\
\text { antimikrobiyaller }\end{array}$ \\
\hline
\end{tabular}


boyutlarında ve nispeten $>1 \mu \mathrm{m}$ den daha büyük olabilmektedir. C60 yaklaşık $\sim 1 \mathrm{~nm}$ çapındadır. Metal ve Metal oksit MNm'lerin en yaygın olanları; değişik bileşiklerde cadminyum, galyum arsenür, altın, nikel, platin, gümüş, alüminyum oksit (alümina), seryum dioksit (ceria), silikon dioksit (silika), titanium dioksit ( $\mathrm{TiO} 2$, titanyum) ve çinko oksittir.

MNm'leri, enzimler gibi ana hücre mekanizmaları ve bileşenleri ile aynı boyut aralıklarına sahiptirler. Bu özellikleri nanomateryallerin vücutta enzimler gibi biyokimyasal tepkimeye girebilmeleri potansiyelini ortaya çıkarmaktadır [1,5]. Bu durum MNm'lerinin örneğin akciğerlerde birikim yaparak, akciğerlerden diğer sistemik bölgelere geçip şiddetli inflamatuar yanıt oluşturma potansiyellerini akla getirmektedir [1]. Bu özellikleri de nanomateryalleri insan ve çalışan sağlığı bakımından dikkatle izlenmesi ve değerlendirilmesi gereken bir kategoriye sokmaktadır.

\section{Fiziksel ve Kimyasal Özellikleri}

Nanomateryallerin fiizksel ve kimyasal özellikleri üretimde avantaj sağlayıcı bir ürün olmalarını sağlamaktadır. $\mathrm{Bu}$ özellikler aynı zamanda nanomateryallerin davranış biçimlerinin belirlenerek, çalışan sağlığına olan etkisinin değerlendirilmesinde dikkate allınması gereken bir konudur. Gerek proseslerin devamının sağlanması, gerekse çalışan güvenliğinin izlenebilmesinde kullanılan Nanopartiküllerin ölçümesi ve test edilmesi gereken karakteristik özellikleri ile ilgili OECD ve ISO seviyesinde tartışmalar devam etmektedir [6].

İş sağlığı ve güvenliği açısından Nanopartikül ile ilgili değerlendirilmesi gereken ana parametreler şunlardır:

\section{Fiziksel}

- Boyut, şekil, spesifik yüzey alanı, en boy oranı

- Aglomerasyon / agregasyon hali

- Boyut dağılımı
- Yüzey morfolojisi/topoğrafisi

- Kristallenme ve hata yapıları

• Çözünürlük

Kimyasal

- Yapısal formül / Moleküler yapı

- Nanomateryal kompozisyonu (saflık derecesi, bilinen safsizlıklar)

- Faz Ayrımı

- Yüzey kimyası (kompozisyon, yük, gerilim, reaktif alanlar, fiziksel yapı, fotokatalitik özellikler, zeta potansiyeli)

- Hidrofilisite/lipofilisite

Nanomateryaller, çalışma ortamında havada asılı (ultraince partiküller, nanopartiküller, aerosoller), sıvıda asilı (koloid) ve katılarla birleşmiş nanotozlar olarak bulunabilirler. Biyolojik güvenlik değerlendirmesi için $\mathrm{MNm}$ ’erin uygun bir ortamda dağıtılması gerekmektedir. Bu ortam ve nanomateryaller arasındaki etkileşim süspansiyonun davranışını da derin bir şekilde etkileyecektir [7].

\section{MARUZIYET}

Nanomateryallere maruziyet başta çalışanların maruziyeti olmak üzere kullanıcıların maruziyeti, atık yoluyla maruziyet, ortam maruziyeti ve çevresel maruziyet şeklinde gerçekleşir. Maruziyet değerlendirmesi nanomateryalin sentezlenmesinden atılmasına kadar tüm üretim ve kullanım döngüsünü kapsamaktadır. Maruziyet değerlendirmesinde spesifik ürünler için nanopartikül maruziyetinin oluşup oluşmayacağını belirlemek potansiyel riskleri değerlendirmek için kritik olan ilk aşamadır [9].

İdeal olarak maruziyet değerlendirmesi herbir hedef grup için maruziyet seviyelerinin kantitatif ölçümü üzerine olmalıdır. Ancak pratikte güvenilir maruziyet verileri oldukça yetersizdir ve ortam ile sınırlı kalmıştır. Bu nedenle 
çoğu durumda maruziyet seviyelerinin değerlendirilmesinde maruziyet tahmin modelleri baz alınmaktadır (Örneğin: Şekil 1. REACH (Registration, Evaluation, Authorization and Restriction of Chemicals-Avrupa Birliği Kimyasallar Kayıt Değerlendirme ve Yetkilendirme) maruziyet değerlendirme yaklaşımı [10].

Şekil 1: REACH Maruziyet Değerlendirmesi Yaklaşımı [10]

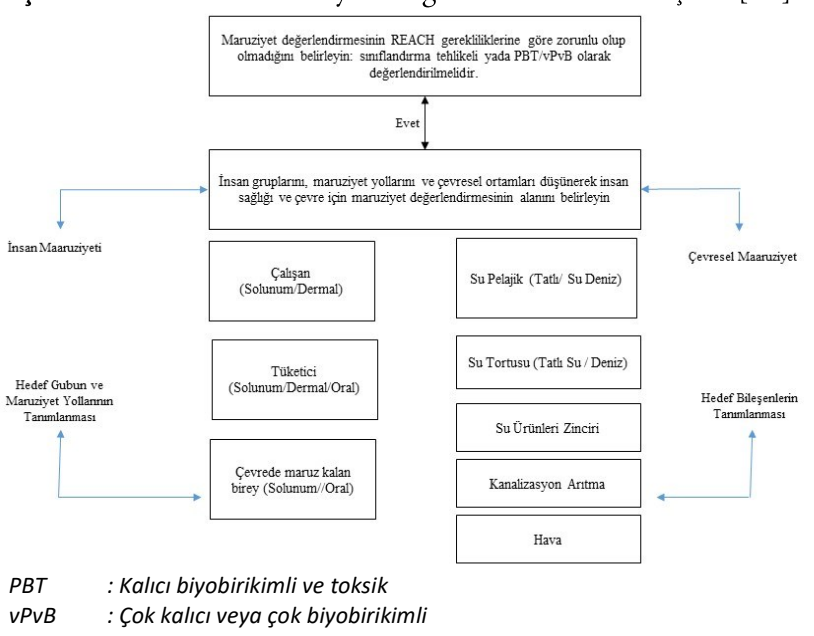

Nanomateryallere Maruziyet dermal, solunum, oral, sindirim yada enjeksiyon gibi farklı yollarla gerçekleşmektedir. Bu nedenle iş sağlığı ve güvenliğinde operatif kurulum içerisinde en muhtemel maruziyet yolu düşünülmeli ve bununla ilgili maruziyet belirleyicileri test ve ölçüm parametreleri seçilmeldir [8].

REACH (EC) No 1907/2006 yönetmeliğine göre kimyasal güvenlik değerlendirmesi yapılmasının amacı, herbir üretim döngüsünde nanopartiküllerin güvenli kullanımının sağlanmasıdır. Kimyasal Güvenlik Değerlendirmesi maruziyet oluşum senaryosu, maruziyetin tahmin edilmesini ve risk karakterizasyonunu içermektedir. Konsept olarak maruziyet değerlendirmesinde baz alınan özellikler nanomateryal dozunun yada konsantrasyonun ölçümü işlemidir. Maruziyet ölçümü ve değerlendirilmesi potansiyel (eko) toksikolojik etkilerin olşabilmesinde önemli bir parametre olmasından dolayı risk analizinde önemli bir aşamadır [10]. Nanopartikül (NP) üretim proseslerinde ortaya çıkabilecek Maruziyet Riskleri Tablo 2.'de gösterilmiştir.

\section{Test ve Ölçüm}

Çalışanların maruz kaldıkları toz ve materyallerin sürekli test ve ölçümü üretim döngüsünün her aşamasında önemli bir etkendir. Akut yada kronik maruziyet sonucunda çevresel ortamlarda test maddelerinin potansiyel etkilerini belirlemek için OECD test yönetmeliklerinde tanımlanmış olan basit ekotoksikolojik yönetmeliklerin nanomateryaller için yeterli ve uygun olduğu düşünülmektedir. Ancak OECD nanomateryallerin testi için bu yönetmeliklerin spesifik olarak tasarlanmadığını da kabul etmektedir ve ölçübilimi, numune hazırlama, test maddelerinin iletimi, maruziyet miktarları, doz metrikler ve ölçümlerin nanomateryallerin test edilmesi için yeterli olmadığı düşünülmektedir.

Test ve Ölçüm methotları (Tablo 3) için gerekli olan ve dikkate alınması gereken potansiyel spesifik özellikler şun-

Tablo 2: Nanopartikül Üretim Prosesleri Esnasında Potansiyel Maruziyet [23]

\begin{tabular}{|c|c|c|c|}
\hline Proses Sentezi & Partikül Formasyonu & Potansiyel Solunum Riski & Potansiyel Dermal ve Sindirim Riski \\
\hline Gaz Fazı & Havada & $\begin{array}{l}\text {-Reaktörden direk sızınt ve } \\
\text {-Ürün kurtarma }\end{array}$ & $\begin{array}{l}\text { Aeresol partikül kirliliği } \\
\text { Ürün İşleme } \\
\text { Ekipman temizliği/bakım }\end{array}$ \\
\hline Buhar Birikimi & Substrat Alt Tabaka & $\begin{array}{l}\text {-Reaktörden ürün kurtarma ve Prosesleme } \\
\text { paketleme }\end{array}$ & $\begin{array}{l}\text { Çalışma ortamında kuru toz kirliliği } \\
\text { Ürün işleme } \\
\text { Ekipman temizliği/bakım }\end{array}$ \\
\hline Koloidal & Sıvı Süspansiyon & -Kurutma, prosesleme ve ürün dökümü & $\begin{array}{l}\text { Çalışma ortamında dökülme/kirlilik } \\
\text { Ürün işleme, Ekipman temizliği/bakım }\end{array}$ \\
\hline Aşınma & Sıvı Süspansiyon & -Kuruma, prosesleme ve ürün dökümü & $\begin{array}{l}\text { Çalışma ortamında dökülme/kirlilik } \\
\text { Ürün işleme, Ekipman temizliği/bakım }\end{array}$ \\
\hline
\end{tabular}


Tablo 3: Nanomateryal Maruziyetin Değerlendirilmesinde Kullanılan Ölçüm Methotları ve Araçları [23].

\begin{tabular}{|c|c|c|}
\hline Metrik & Methot & Methot Bilgisi \\
\hline \multirow{6}{*}{ Kütle } & Boyut seçimli özel örnekleyici & $\begin{array}{l}\text { Nm boyut aralığında boyut fraksiyonlu bir cihaz halen yoktur. Buyüzden gravimet- } \\
\text { rik yada off-line kimyasal analiz gereklidir. Kütle aynı zamanda boyut dağılımı ile } \\
\text { tahmin edilebilir. }\end{array}$ \\
\hline & Boyut seçimli statik örnekleyici & $\begin{array}{l}\text { 100nm (10 nm'ye kadar) bir kesim noktası sunan cihazlar Cascade Impactor cihaz- } \\
\text { larıdır. }\end{array}$ \\
\hline & Konik element salınımlı Mikrobalans (TEOM) & $\begin{array}{l}\text { TEOM gibi hassas gerçek-zamanlı izleyiciler nanoaeresol kütle konantrasyonunu } \\
\text { boyut seciçi bir giriş ile on-line ölçmek için kullanışlı olabilir. }\end{array}$ \\
\hline & Taramalı Mobilite Parçacık Boyutlandırıcı (SMPS) & $\begin{array}{l}\text { Boyutları } 3 \mathrm{~nm}-800 \mathrm{~nm} \text { arası partiküllerin elektriksel mobilitesi üzerine baz } \\
\text { alınmış Gerçek-zamanlı boyut-seçici tespit }\end{array}$ \\
\hline & Elektrikli Düşük Basınç Darbe Ölçer (ELPI) & $\begin{array}{l}\text { Partikül yüklerine göre ve ataletine göre Gerçek-zamanlı boyut-seçimli tespit. } \\
\text { Veriler konsantrasyon açısından yorumlanabilir. }\end{array}$ \\
\hline & Nanomater Aeresol Sampler & Alınmışörneğin yüzey analizinde kullanılmasına yardımcı olur \\
\hline \multirow{4}{*}{ Miktar } & Optik Partikül Sayıcı (OPC) & 300 nm'den daha küçük partiküller tespit edilemez. \\
\hline & Yoğunluk Partikül Sayıcı (CPC) & 100 nm'ye kadar gerçek-zamanlı konsantrasyon miktarı \\
\hline & SMPS & 3-800 nm çapında mobiliteye göre gerçek-zamanlı boyut seçimli tespit \\
\hline & ELPI & $\begin{array}{l}\text { Partikül yüklerine göre ve ataletine göre Gerçek-zamanlı boyut-seçimli tespit. } \\
\text { Veriler konsantrasyon açısından yorumlanabilir. }\end{array}$ \\
\hline \multirow{5}{*}{ Yüzey Alanı } & Epiphaniometer & Yüzey alanlarına göre radyoaktif etiketleme \\
\hline & Difüzyon yükleyici & $\begin{array}{l}\text { Yüzeyin pozitif iyonlarına tutunmaya göre } 100 \mathrm{~nm} \text { 'den daha küçük partiküllere } \\
\text { hassas. Örnek hazırlama gerekir }\end{array}$ \\
\hline & SMPS & 3-800 nm çapında mobiliteye göre gerçek-zamanlı boyut seçimli tespit \\
\hline & ELPI & $\begin{array}{l}\text { Partikül yüklerine göre ve ataletine göre Gerçek-zamanlı boyut-seçimli tespit. } \\
\text { Veriler konsantrasyon açısından yorumlanabilir. }\end{array}$ \\
\hline & BET (Brunauer, Emmett ve Teller Methodu) & Partikül yüzeyinde gaz $\left(\mathrm{N}_{2}\right)$ adsorpsiyonuna göre tahmin. \\
\hline $\begin{array}{l}\text { Görüntü } \\
\text { Analizi }\end{array}$ & $\begin{array}{l}\text { Taramalı Elektron mikroskobu(SEM), Geçirimli } \\
\text { Elektron mikroskobu(TEM) }\end{array}$ & $\begin{array}{l}\text { Nanopartiküllerin belirlenen alanlarının analizi. Numuneler özel örnekleyici yada } \\
\text { boyut seçimli static örnekleyici ile toplanabilir. }\end{array}$ \\
\hline
\end{tabular}

lardır [8]:

\begin{tabular}{|c|c|c|}
\hline Fizikokimyasal özellikler & $\underline{\text { Toksikolojik }}$ & Ekotoksikoloijk noktalar \\
\hline Partikül şekli & Hücre alımı & Havalandırma oranı \\
\hline Yüzey alanı ve enerjisi & Hücre canlılığı & Soluma patolojileri \\
\hline Dağılma hali & Oksidatif stress & Mukus salgısı \\
\hline Aglomerasyon hali & İnflamasyon & Beyin patolojisi \\
\hline Yüzey yükü ve kimyası & Fibroz & Hayvan davranışları \\
\hline Redoks potansiyeli & İmmünotoksisite & $\begin{array}{l}\text { Oksidatif stress biyo- } \\
\text { işaretleyicileri }\end{array}$ \\
\hline $\begin{array}{c}\text { Hücresiz reaktif oksijen } \\
\text { türleri }\end{array}$ & Kardiyovasküler toksisite & \\
\hline
\end{tabular}

\section{RİSK YÖNETİMI}

\section{A. Risk Sınıflandırma Sistemleri}

Değerlendirme metodolojilerindeki ilerlemelere rağmen, tüm nanomateryaller için belirleyici özelliklerin geniş kapsamlı bir karakterizasyonu halen tam anlamıla yapılamamıştır. Bu nedenle bazı araştırmacılar nanomateryaller için risk sınıflandırmasını yada birincil risk derecelendirmesini önermişlerdir. Yapılan bazı çalışmalarda quantum dotlar, fullerenler, tek duvarlı karbon nanotüpler ve karbon siyahının derecelendirilmesi için fizikokimyasal ve toksisite verileri baz alınırken [3, 11], bazı çalışmalarda sınıflandır- 
ma sistemi için ise toksisite ve kararlılık üzerinde durulmuş ve nano-toksisiteyi belirlediğinden dolayı kararlılığın birinci sırada karakterize edilmesi gerektiği tavsiye edilmiştir $[3,12]$. Bazı çalışmalarda da Nanomateryaller için toksisite ve fizikokimyasal özellikleri ölçen bir dizi performans ölçüsü belirlenmiştir. Parametreleri ise aglomerasyon (topaklanma), agregasyon (yığılma), reaktivite, yük, kritik fonksiyon grupları, boyut, biyoelverişlilik, biyobirikim ve toksik potansiyel olmuştur $[3,13]$.

\section{B. Nano Toksikoloji}

Nanotoksikoloji ekosistemlerde ve yaşayan sistemlerde mühendislik nanomateryallerinin biyolojik etkileri üzerine yapılan çalışmalardan ve klasik toksikolojiden ortaya çıkmıştır. Klasik toksikoloji ölçümlerinin nanomateryallere de uygulanabileceği ancak modifiye edilmesi gerektiği üzerine ortak bir kanı vardır [3].

Çeşitli nanomateryal formlarda yapılmış çalışmalarda (C60, tek-çok duvarlı karbon nanotüpler) toksikolojinin doz-miktar ile ilişkili olduğu bulunmuştur. Ancak mevcut nanopartiküllerin toksisitesi sadece kütle ile değil fiziksel, kimyasal özelliklerle de ilişkilidir. Örneğin düşük çözünürlüklü ve düşük toksisiteli partiküllerde yüzey alanı inflamasyon açısından toksisiteyi daha belirleyici olmaktadır [8].

\section{Risk Değerlendirmesi}

Nanospesifik bir risk değelendirmesi klasik kimyasallar için bulunan mevcut standart stratejilerin ötesine geçmektedir. SCENIHR ve EFSA gibi AB komiteleri mevcut risk değerlendirme prosedülerini onaylamış (Şekil 2) ve bu methotların nanomateryallere uygulanabileceğini ancak spesifik alanların gelişime ihtiyaç duyduğu sonucuna varmıştır [3, 14, 15]. SCENIHR standart risk değerlendirme prosedürünün gelişimi için yaşam döngüsü methodolijisi $[3,16]$ yada ön sınıfladırma sistemleri gibi ilave teknik araçları da önermektedir $[3,17]$.

Kimyasal bir risk değerlendirmesi için belirleyici unsurlar kimyasalın miktarı, kararlılık yada biyobirikim gibi özellikler ve akut, kronik toksisite, hassasiyet, genotoksisite, üretkenlik toksisitesi yada kanser üretkenliği gibi etkilerdir. Fizikokimyasal özellikler, toksikolojik ve ekotoksikolojik bilgi ise gerekli verileri oluşturmaktadır [3].

Avrupa Kimyasallar Ajansı (ECHA)'na göre bir Kimyasal Güvenlik Değerlendirmesi yapabilmek için ana gereksinimler ise şunlardır:

- Hangi şekil, boyut ve fiziksel halde olursa olsun maddenin fizikokimyasal, toksikolojik ve ekotoksikolojik özellikleri baz alınmış komple bir Tehlike Değerlendirmesinin yapılması,

- Makul kullanım koşulları alında maruziyet seviyelerinin belirlenmesi,

- Maruziyet seviyelerini karşılaştırarak riskin kategorize edilmesidir.

Geleneksel kimyasallar için mevcut olan risk değerlendirme yöntemlerinin MNm'lerine de uygulanabileceği değerlendirmesi yapılmıştır. Ancak MNm’lerine uygulamada spesifik yaklaşımlar gerektirecektir (kullanım birimi

Şekil 2: Risk Değerlendirme Yapısı [9].

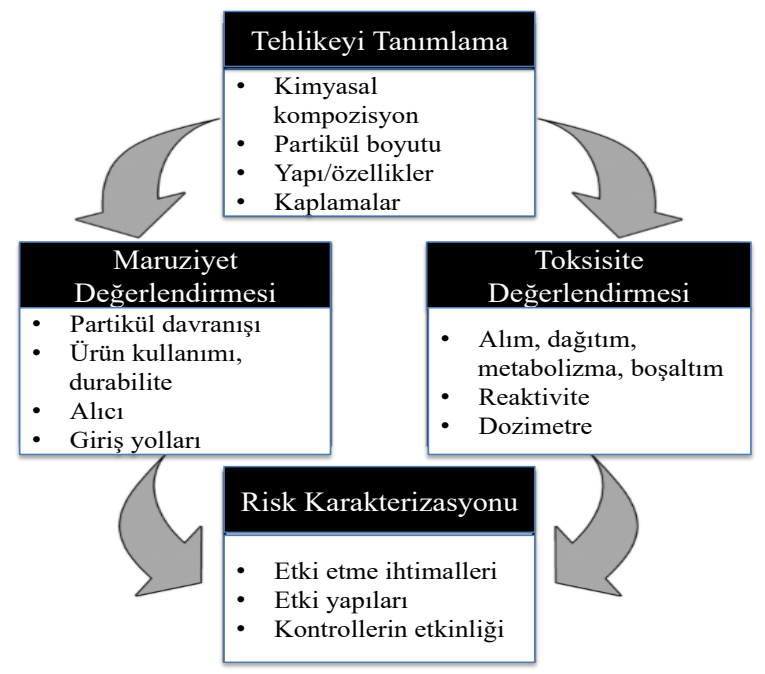


[metric], maruziyet değerlendirme metodolojisi, vb). Şimdiye kadar kullanılmış ve uygunluğu kabul gören risk değerlendirme methodolojileri bulunsada (Tablo 4) MNm'leri ile ilgili standartlaşmış bir risk değerlendirme methodolojisi tam anlamıyla bulunmamaktadır. Nanoölçekli maddelerle ve ultra-ince partiküller ile yapılan çalışmalar nanomateryallerin risk değerlendirmesi yapısı (Şekil 2.) için başlıca gereksinimleri ortaya koymaktadır.

\section{Tehlikenin Tanımlanması}

Tehlikenin tanımlanması partiküllerin çeşitli karakteristiklerine bağlıdır. Yeni yapıların tehlikeleri daha önceden küçük boyutlarda çalışılmış aynı maddelerin ( $\mathrm{TiO} 2, \mathrm{ZnO}$ gibi metal oksitler) tehlikelerinden daha az tahmin edilebilir durumdadır. Yüzey kaplaması yada bir matriks içerisin-

Şekil 3: Nanopartiküller için Tehlike Algoritması [8]

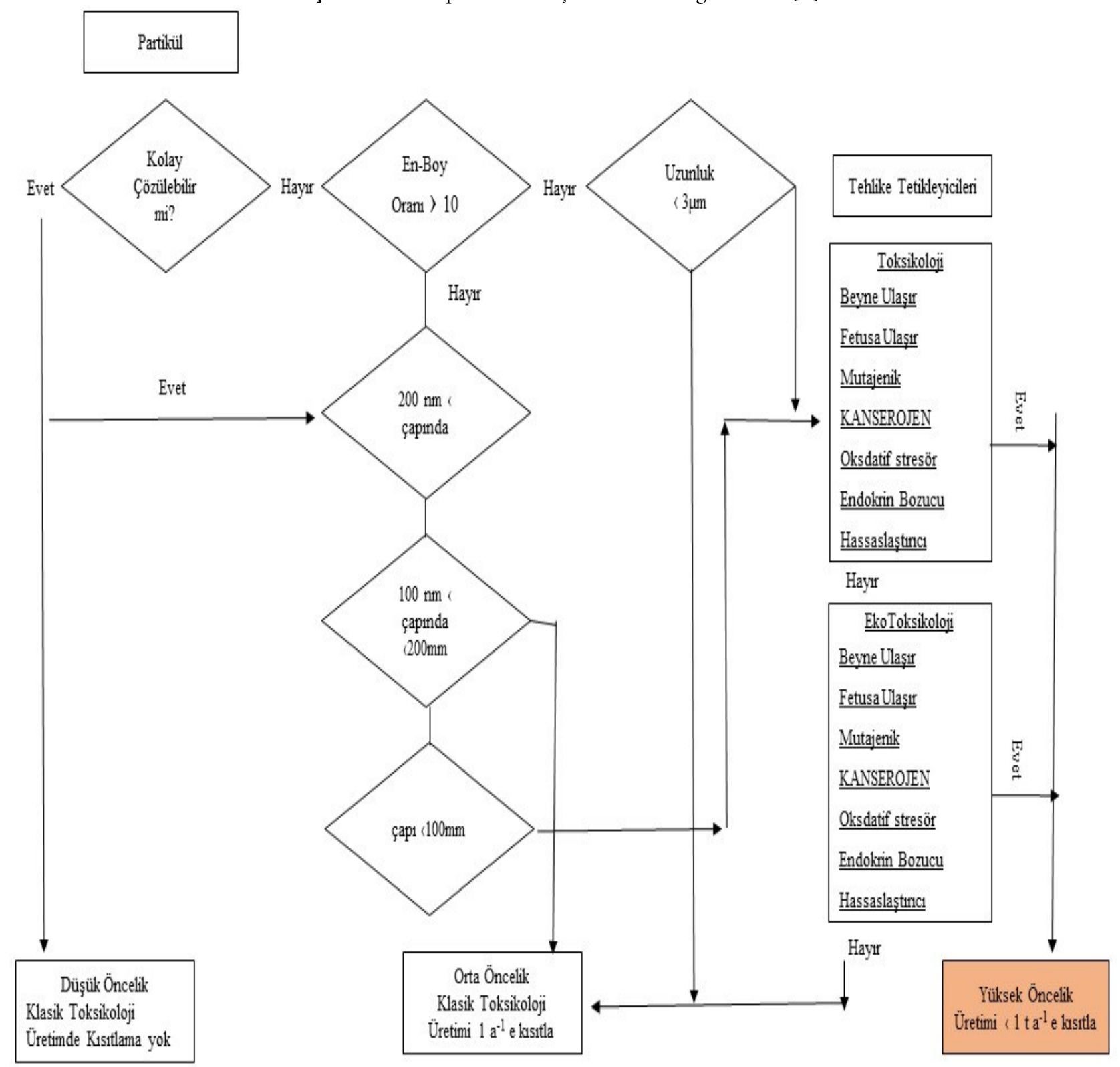

Not: Karar Esnasindabilinmeven değerler Evet olarak alnmalddr. 
de materyalin enkapsülasyonu nanopartiküllerin biyolojik mobilitesini ve reaktivitesini etkilemektedir $[9,18]$. Nanopartiküller ile ilgli karşılaştırmalı bir tehlike değerlendirmesi Howard \& de Jong (2004) tarafından önerilmiştir ve bir tetikleyici algoritma geliştirmiştir (Şekil 3). Maruziyet değerlendirmesi yapılmamış ve maddeler tehlikesine göre değerlendirilmiştir [19]. Bu algoritmada nanopartiküller, çözünebilirlik, boyut, en-boy oranı gibi özelliklerine göre bir tehlike değerlendirmesi yapısı çıkarılmışır.

\section{Risk Değerlendirmesi}

Nanoteknolojik Risk değerlendirmesinin şimdiye kadar Risk Yönetimi Konseptinin belirlenmesi (Örn: IRGC Risk Governance Framework), Risk Yönetim Sistemleri belirlenmesi ve Risk Analiz Methotları (Örn: Control Banding Nanotool) geliştirilmesi kaydetmiş olduğu sistematik yaklaşımlardır.

\section{Risk Derecelendirmesi}

Risk derecelendirmesi basit olması nedeniyle en yaygın risk değerlendirme yollarından biridir. Kimyasal risk değerlendirmesinin aksine uzman yorumuna dayanmaktadır. Tahminler kalitatiftir (nitel). Burgman (2005) beş aşamalı bir yaklaşım önermiştir [20, 22].

- Uzman yorumlarına dayalı risk derecelendirmesi üzerine karar verilmektedir.

- İkinci açamada olaylar tanımlanmaktadır.

- Tanımlanan her bir olay değerlendirilmektedir.

- Değerlendirilen riskler kabul edilebilir seviyeler ile karşılaştırılmaktadır.

- Son aşama ise seçilen risklerin yönetimi aşamasıdır.

Olayların değerlendirldiği üçüncü aşamada iki tehlike parametresi bulunmaktadır. İlki istenmeyen olayın (1-5 arası puanlamalı) oluşmma ihtimalidir. İkinci parametre ise (1-5 arası puanlamalı) olayın sonucudur. Kullanımı yaygın bir yöntem olan Risk matrisi ile nihai değerlendirme sonucuna ulaşılmaktadır.

\section{Kimyasal Derecelendirme ve Skorlama}

Kantitatif bir risk değerlendirmesi değildir ancak risk değerlendirmesine yardımcı olarak kullanılabilir. Maddeler arasında önceliklendirmeye olanak sağlar. Risk derecelendirme methodu gibi uzman yorumuna dayanmaktadır. Dört aşamalıdır;

- İlk aşama hedefin tanımlanması ve aşamalandırılmasıdir.

- İkinci aşama ise parametrelerin değerlendirileceği indikatörün seçimidir. Bu aşamada aynı zamanda hangi verilere ihtiyaç olacağı belirlenmektedir (toksisite, kararlılık, üretim, kullanım, vb).

- Üçüncü aşama ise ikinci aşamadaki tehlike parametreleri baz alınarak derecelendirme ve skorlamadır. Kimyasal derecelendirme ve skorlama çok çeşitli tipte olabilir ama en yaygını eğer-olursa tipidir. (Örneğin eğer toksisite $1 \mathrm{mg} / \mathrm{l}$ II geçerse o zaman toksik sayılır.)

- Son aşama ise karar vermek için sonuç ve sunum aşamasıdır.

\section{Kontrol Bandı (Control Banding - CB)}

Kontrol Bandı tehlikeli kimyasallara mesleki maruziyeti kontrol etmek için eczacılık endüstürisine yönelik tasarlanmıştır ve diğer endüstürilerde de yaygın olarak kullanılmaktadır [20, 21]. Risk derecelendirmesi, kimyasal derecelendirmeye benzerdir ve kalitatif (nitel) bir metottur. Mesleki sağlık risklerine odaklanmıştır ve çevresel riskleri içermez. Farklı risk ve tehlike kalıplarında bir maddenin belirli bir tehlike bandında kategorize edilmesidir. Ayrıca uçuculuk ve tozluluk gibi maruziyet-ilişkili özelliklere göre maruziyet-ilişkili bantlara göre ve kullanımdaki miktar maruziyet bantlarına kategorize edilebilir. Tehlike ve maruziyet olarak iki puan skalası bulunmaktadır (risk derecelendir- 
Tablo 4: Nanoteknolojide kullanılan yaygın Risk Analiz Metotları [20, 24]

\begin{tabular}{|c|c|c|}
\hline S.Nu. & Risk Analiz/Değerlendirme methotları & $\begin{array}{l}\text { Control } \\
\text { Banding }\end{array}$ \\
\hline 1 & $\begin{array}{l}\text { ANSES, Development of a Spesific Tool for nano- } \\
\text { materials }\end{array}$ & $C B$ \\
\hline 2 & CB Nanotool 2.0-Control Banding & $C B$ \\
\hline 3 & $\begin{array}{l}\text { Nanotoolkit-Working Safely with Engineered Na- } \\
\text { nomaterials in Academic Research Settings }\end{array}$ & \\
\hline 4 & Nanotechnology Risk Asesment Model- ISPESL & $C B$ \\
\hline 5 & Early warning signs & \\
\hline 6 & Genaidy method & \\
\hline 7 & Groso method & $C B$ \\
\hline 8 & $\begin{array}{l}\text { Guidance working safely with nanomaterials and } \\
\text { nanoproducts- The Guidance }\end{array}$ & $C B$ \\
\hline 9 & Hierarchical Aggregation & \\
\hline 10 & LICARA nanoSCAN & \\
\hline 11 & Nano-Evaluris & \\
\hline 12 & NanoHAZ & \\
\hline 13 & NANoREG & \\
\hline 14 & NanoRiskCat & $C B$ \\
\hline 15 & NanoSafer & $C B$ \\
\hline 16 & Occupational Hazard Band for Nano & $C B$ \\
\hline 17 & $\begin{array}{l}\text { Precautionary Matrix for Synthetic Nanomaterials- } \\
\text { (PM) }\end{array}$ & $C B$ \\
\hline 18 & Relative Risk Analysis & \\
\hline 19 & Risk Trigger Scores & \\
\hline 20 & Stoffenmanager Nano- STM-Nano & $C B$ \\
\hline 21 & TEARR & \\
\hline 22 & WCD model & \\
\hline 23 & $\begin{array}{l}\text { ISO/TR 131121, Nanotechnologies-Nanomaterials } \\
\text { Risk evaluation }\end{array}$ & \\
\hline 24 & $\begin{array}{l}\text { Work health and Safety assessment tool for hand- } \\
\text { ling engineered nanomaterials }\end{array}$ & $C B$ \\
\hline 25 & Risk identification framework & \\
\hline 26 & $\begin{array}{l}\text { ASTM E2535-07 Standart Guide for Handling Un- } \\
\text { bound Engineered Nanaoscale Particles in Occupa- } \\
\text { tional Setting }\end{array}$ & \\
\hline 27 & Risk Based Classification System of nanomaterials & \\
\hline 28 & $\begin{array}{l}\text { Management of nanomaterials safety in research } \\
\text { environment }-E P F L\end{array}$ & $C B$ \\
\hline 29 & Assured Nano & \\
\hline 30 & Safe Handling and use of carbon nanotubes & \\
\hline 31 & $\begin{array}{l}\text { General Risk Mangement Systems- Chemical Cont- } \\
\text { rol Kit (CCK) }\end{array}$ & \\
\hline 32 & Nanosafety Guidelines- TU-Delft guidelines & \\
\hline
\end{tabular}

CB: Kontrol bandı yöntemi baz alınan methotlar mesine benzer olarak şiddet ve ihtimal olarak ta isimlendirilebilir). En yaygın kullanılan bant methodu ise UK Sağlık ve Güvenlik idaresi tarafindan geliştirilen The Control of Substances Hazardous to Health Essentials(COSHH)'tır [20].

Birçok kontrol bandı kalitatif (nitel) risk değerlendirmesi (risk tehlike/şiddet ve maruziyet/ihtimal) üzerine baz alınmıştır ve bilimsel belirsizlik nedeniyle kantitatif olmasına gerek bulunmamaktadır. Web ortamında tehlikeyi ve maruziyeti farklı şekillerde ve parametrelerde ilişkilendiren kontrol bandı araçları da bulunmaktadır [8].

Risk Analizinin bir çok methodu bulunmaktadır. Nanomateryaller için Risk Analizi yeni proseslere, üretilen ürünlere, sağlık risklerine göre yöntemsel olarak gelişmeye devam etmekte, şekillenmektedir. Nanoteknoloji alanlarında en yaygın kullanılan Risk Analiz metotları Tablo 4.'te gösterilmiştir.

Kullanılan risk analizlerinde farklı şekillerde sonuçlara ulaşılmaktadır. Ancak Kontrol Bandı metotlarında sonuçlara Tehlike\&/Maruziyet yada Şiddet\&/İhtimal puanlamaları yapılarak tipik Risk Matrisleri ile ulaşılmaktadır. Örnek olarak Nano Safer da kullanılan bir Risk Matrisi Şekil 4.'te verilmiştir [25].

Şekil 4: NanoSafer Risk Matrisi Örneği; Maruziyet ve Toksisite (4 kontrol bantlı) [25]

\begin{tabular}{|c|c|c|c|c|}
\hline $\begin{array}{c}\text { Toxicity } \\
\text { Exposure }\end{array}$ & $0.76-1.00$ & $0.51-0.75$ & $0.25-0.50$ & $0.00-0.25$ \\
\hline$>1.00$ & RL5 & RL5 & RL5 & RL5 \\
\hline $0.51-1.00$ & RL5 & RL5 & RL4 & RL4 \\
\hline $0.26-0.50$ & RL5 & RL4 & RL4 & RL3 \\
\hline $0.11-0.25$ & RL4 & RL4 & RL3 & RL2 \\
\hline$<0.11$ & RL4 & RL3 & RL2 & RL1 \\
\hline
\end{tabular}

8 saatlik Mesleki Maruziyet. RL1: En düşük Risk, RL5: En Yüksek Risk

Bazı Nanoyapılar için kullanılmış Risk Değerlendirme Metotları Tablo 5.'te gösterilmiştir. 
Tablo 5: Literatürdeki Nanoteknolojik Objeler türüne göre kullanılan Bazı Risk Değerlendirme Metotları [20]

\begin{tabular}{|c|c|}
\hline Metod & Değerlendirme Objesi \\
\hline ANSES, & Nanomateryaller \\
\hline CB Nanotool 2.0 & Nanopartiküler \\
\hline Early warning signs & Nanomateryaller \\
\hline Genaidy method & Karbon nanofiber üretimi \\
\hline Groso method & Nanolabaratuvarlar \\
\hline The Guidance & Nanomateryaller ve Nanoürünler \\
\hline Hierarchical Aggregation & Nanomateryaller \\
\hline LICARA nanOSCAN & Nanoürünler \\
\hline Nano-Evaluris & Nanotozlar \\
\hline NanoHAZ & Nanomateryaller \\
\hline NANoREG & Nanomateryaller \\
\hline NanoRiskCat & Nanoürünler \\
\hline NanoSafer & Nanomateryaller \\
\hline Occupational Hazard Band for Nano & Uçucu Partiküller \\
\hline Precautionary Matrix for Synthetic Nanomaterials-PM & Nanopartiküler ve Nanorodlar \\
\hline Relative Risk Analysis & Nanomateryal üretim prosesi \\
\hline Risk Trigger Scores & Nanoürünler \\
\hline Stoffenmanager Nano- STM-Nano & Nanopartiküler \\
\hline TEARR & Nanomateryaller (içeren herhangi bir madde) \\
\hline WCD model & Nanomateryaller ve Kimyasallar \\
\hline
\end{tabular}

Yapılmış çalışmalarda farklı Kontol Bandı metotları ile ilgili literatürde yapılan karşılaştırmalar Tablo 6. ve Tablo 7.'te gösterilmiştir.

\section{E. Risk Kontrol Önlemleri}

Sağlık etkileri ve maruziyet limitleri ile ilgili nanomateryaller üzerinde yapılan çalışmalar devam etmektedir. Bu nedenle risk kontrol hiyerarşisindeki basamaklarının kombinasyonu ile iş sağlığı ve güvenliği açısından çalışanlara korunma sağlanmalıdır.

Mevcut tehlikeler elimine edilemiyorsa yada daha az tehlikeli bir materyal ile değiştirilemiyorsa (MNm’lerin spesifik özellikleri için oldukça zor) uygun mühendislik kontrolleri uygulanmalıdır. Proses esnasında bazı MNm’ler agglomeralar oluşturabilmekte ve çalışma ortamından ayrılması güçleşmektedir. Bu durumlarda materyal örneklemesi, ekipman temizliği ve bakımı esnasında koruyucu önlemler alınmalıdır. Havalandırmasız bir ortamda işlemin kapalı hale getirilmesi MNm'lerin penetrasyon özelliği nedeniyle emisyonunu kontrol etmede yeterli olmayabilir [23].

Yüksek etkiye sahip partikül hava filtreleri (en az 0-3 mikrometre çapında mono-dağılıış partiküllerin \% 99.97'sini tutabilen HEPA filtreleri) ile havalandırması sağlanan kapalı alanlarda (havasız ortam kabini, laboratuvar, proses odası) çalışılmalıdır. Proses tam kapalı ortamda yapılamıyorsa üretim esnasında kirliliğin salınımını yakalayabilecek lokal emmeli havalandırma sağlanmalıdır. Hijyen 
Tablo 6: Farklı kontrol bantlarının karakterizasyonları ve karşılaştırmaları [8]

\begin{tabular}{|c|c|c|c|c|c|c|c|c|c|c|c|c|}
\hline \multirow[b]{2}{*}{$\begin{array}{l}\text { Kontrol Bandı Methodu } \\
\text { Kısa Adı }\end{array}$} & \multicolumn{3}{|c|}{$\begin{array}{l}\text { TEHLiKE BANDI } \\
\text { Ayirma Sistemi }\end{array}$} & \multicolumn{7}{|c|}{$\begin{array}{c}\text { MARUZiYET BANDI } \\
\text { Etkinlik Kaynağı/Aktivite Türü }\end{array}$} & \multicolumn{2}{|c|}{$\begin{array}{c}\text { MATRiKS } \\
\text { Bant / Seviye } \\
\text { Miktarı }\end{array}$} \\
\hline & 六 & $\frac{\sqrt{5}}{3}$ & 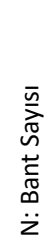 & 茕 & 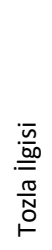 & 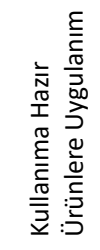 & 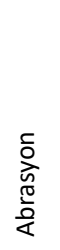 & 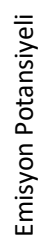 & 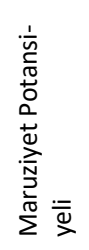 & 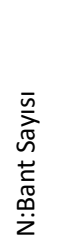 & 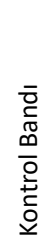 & 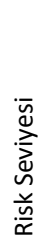 \\
\hline Precautionary Matrix & - & + & 1 & $(+)$ & $(+)$ & $(+)$ & $(+)$ & + & - & 1 & 2 & - \\
\hline CB Nanotool & - & + & 4 & + & + & - & - & + & - & 4 & 4 & - \\
\hline ANSES[ISO-(proactive)] & + & & 5 & $(+)$ & + & + & + & + & - & 4 & 5 & - \\
\hline $\begin{array}{l}\text { Stoffenmanager Nano } \\
\text { [ISO-(retroactive)] }\end{array}$ & + & - & 5 & + & + & + & + & - & + & 4 & - & 3 \\
\hline NanoSafer & + & + & 4 & - & + & - & - & - & + & 5 & & 5 \\
\hline Guidance & + & - & 3 & + & + & + & + & + & - & 3 & 3 & - \\
\hline NanoRiskChat & + & - & 3 & & & + & + & & & 3 & - & - \\
\hline
\end{tabular}

(Precautionary Matrix'in ayrı bir tehlike ve maruziyet bandı yoktur.)

+ kullanılan, - kullanılmayan, (+) açıkça belirtilmeden (dolaylı)

uygulamalarını (El yıkama bölgeleri gibi ) teşvik eden eğitimler verilmelidir. Duş ve kıyafet değişim alanları gibi Nm’lerin taşıyıcilığını önleyecek tesisler belirlenmelidir. $\mathrm{Nm}$ döküntüler için tam bir yönetmelik mevcut değildir ancak eczacilık ve ilaç endüstürisinde kullanılan uygulamalar Nm’lere uygulanabilir. Çalışsan maruziyetini en aza indirecek dekontaminasyon alanları ve $\mathrm{Nm}$ döküntülerin temizlenmesi için prosedürler belirlenmelidir. Örneğin;

- Herbir vardiyada en az birkez temizlik yapılması sağlanmalı, kuru süpürme (silme) yasaklanmalı, HEPA filtreli vakum temizleyiciler ve sslak silme türü kullanılmalıdır [28].

- Temizleme işleminin çalışana teması önlenmelidir.

- Nm'ler ile işlem yapılan yerlerde yiyecek, içecek tüketimi ve saklanması önlenmelidir [23].

Kimyasallar için kullanılan MSDS formları ise tüm nanomateryaller ve nanomateryal içeren karışımlar için hazırlanmalı ve boyut, boyut dağılımı, agregasyon, aglemerasyon hali, morfoloji, kristal yapı, yüzey alanı, tozluluk ve dağılma gibi kritik fiziko-kimyasal karakteristikleri içeren önleyici bir yaklaşım içermelidir. NOISH 2007 ile 2011 yılları arasında hazırlanmış elli adet MSDS formlarının içeriklerini değerlendirmiş ve yetersiz olduklarını belirtmiştir [29]. Solunum ve deri maruziyeti en başta gelen maruziyet olduğundan, uygun eldivenler, koruyucu elbise ve respiratörler personele sağlanmalıdır.

Nanomateryale maruz kalan çalışan, tıbbi taramadan geçirilmeli ve izlenmelidir. OSHA standartlarına (Cadminyum, Solunum Koruma, vb) göre tıbbi izleme gereksinimleri gözden geçirilmelidir [28]. OSHA'nın nanoteknolojik güvenlik ve sağlık konuları sayfası bazı OSHA standartlarının nanomateryallere maruz kalan işçilere uygulanabileceğinin altını çizmektedir. Occupational Safety and 
Tablo 7: Farklı Kontrol Bandı methotlarının dikkate aldığı nano-karakteristik özellikler [26, 27]

TEHLIKE (YADA ŞIDDET) BANDI FAKTÖRLERI

\begin{tabular}{|c|c|c|c|c|c|c|c|}
\hline Tehlike Faktörü & $\begin{array}{l}\text { 岁 } \\
\sum_{<}\end{array}$ & 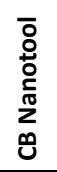 & 㞤 & 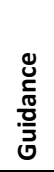 & 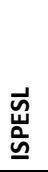 & $\sum_{0}$ & 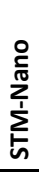 \\
\hline Toxixity (Nano yada Büyük halde) & $\checkmark$ & $\checkmark$ & & $\checkmark$ & $\checkmark$ & & $\checkmark$ \\
\hline Çözünürlük & $\checkmark$ & $\checkmark$ & & $\checkmark$ & & $\checkmark$ & $\checkmark$ \\
\hline Fiber form (Partikül şekli) & & $\checkmark$ & $\checkmark$ & $\checkmark$ & & & $\checkmark$ \\
\hline Reaktivite & $\checkmark$ & $\checkmark$ & & & & $\checkmark$ & \\
\hline Boyut & & $\checkmark$ & & & $\checkmark$ & & $\checkmark$ \\
\hline Yanma yada patlama & & $\checkmark$ & & & $\checkmark$ & & \\
\hline \multicolumn{8}{|c|}{ MARUZIYET (YADA IHTIMAL) BANDI } \\
\hline Miktar & & $\checkmark$ & $\checkmark$ & & & $\checkmark$ & $\checkmark$ \\
\hline Süre/Sıkılık faktörü & & $\checkmark$ & & & $\checkmark$ & $\checkmark$ & $\checkmark$ \\
\hline Materyal hali(kat,,sıvı vb) & $\checkmark$ & & $\checkmark$ & & & & $\checkmark$ \\
\hline Nanoobjelerin ortama salınımı (Toz vb) & $\checkmark$ & $\checkmark$ & & $\checkmark$ & & $\checkmark$ & $\checkmark$ \\
\hline Agregasyon/Aglomerasyon & & & $\checkmark$ & & $\checkmark$ & & \\
\hline Matriks içine katıştırılmış & & & & $\checkmark$ & & $\checkmark$ & $\checkmark$ \\
\hline Çalışan miktarı & & $\checkmark$ & & & $\checkmark$ & & \\
\hline Risk Kontrol/Organizasyon & & & & & $\checkmark$ & & $\checkmark$ \\
\hline Kapsama (Containment) & & & $\checkmark$ & $\checkmark$ & & & \\
\hline Prosesin/işin Türü & $\checkmark$ & & $\checkmark$ & & & & $\checkmark$ \\
\hline
\end{tabular}

Health Act'in 5(a)(1) bölümünde genel görev maddesi (The General Duty Clause )'de aynı zamanda çalışanların nanomateryallere maruz kaldığ 1 durumlarda uygulanabilir [28].

\section{SONUÇ}

Nanomateryallere iş sağlığı açısından maruziyet yeni bir durum olmakla beraber İSG açısından öneminin giderek artacağı değerlendirilmektedir. Nanoteknolojik prosesler nedeniyle ortaya çıkan nanopartiküller ve nanomateryallerin iş sağlığı ve güvenliği açısından hali hazırdaki veri ve bilgi eksikliğinden dolayı geri dönülmez sonuçlar doğurmaması için ihtiyatlı ve tedbirli olunması gerekmektedir.
Nanomateryallere maruz kalan çalışanlar için ciddi sayılacak sağlık riskleri bulunmaktadır. Bilimsel çalışmalar göstermektedir ki nanopartiküller aynı kompozisyondaki ve daha büyük partiküller'den biyolojik olarak daha reaktiftirler ve bu nedenlede özelllikle solunumla maruziyet büyük bir sağlık riski oluşturmaktadır. Benzer kimyasal kompozisyonda ve daha büyük boyuttaki partiküller için mesleki maruziyet limitleri (OSHA Permissible Exposure Limits, NOISH recommended Exposure Limits, ACGIH Threshold Limit Values) olmasına rağmen MNm’leri için mevzuatla bir kurallar bütünlüğü içerisinde spesifik maruziyet limitleri tam anlamıyla belirlenmemiştir.

$\mathrm{Bu}$ bağlamda mevcut yapılmış ve gelecekte yapılacak epidemiyolojik çalışmalar, vivo/vitro ve toksikolojik çalış- 
malar, maruz kalan bireylerin sağllğı ve oluşabilecek meslek hastalıkları açısından ışı tutacaktır. Ultra-ince partiküllerin (örneğin asbestoz) insan sağlığına verdiği zararlar yıllar sonra anlaşılmış ancak bu noktadan itibaren verdiği zararlar geri çevrilememiştir. Ultra-ince partiküllerin boyut açısından ve verebileceği zararlar açısında İş Sağlığı ve Güvenliğinde edindiği aşamalara ele alındığında MNm’ler için çalışanları ve maruziyet gruplarını korumak için tutarlı bir risk yönetimi gerekmekte ve mevcut kimyasallar için uygulanan klasik risk yönetimi metotları yeterli sayılsa bile henüz tam kapsamlı bir metot bulunmadığı da dikkate alınmalıdır.

Nanomateryaller için başlangıçtan son ürüne ve tüketiciye ulaşana kadar tüm üretim döngüsü içerisinde iş sağlığı ve güvenliği açısından kurallar ve standartlar bütünlüğüne ihtiyaç bulunmaktadır. İş Sağlığı ve Güvenliği kültüründe Nanoteknoloji kendine sürekli yeni yerler edinecek ve yeni gelişmeler olacaktır. Ülkemizde İş sağlığı ve Güvenliği sistemi tam anlamıyla oturmamıs ve kendi yerini bulma süreci gerek kanun ve yönetmelikler düzeyinde, gerekse de kültür edinme seviyesinde devam etmektedir. Gelişimi dünya çapında devam eden Nanoteknolojik İş Sağlığı ve Güvenliği ülkemiz içinde oldukça yeni bir çalışma alanıdır. $\mathrm{Bu}$ nedenle bu alanda çalışan işletme ve kuruluşlar tarafından nanoteknolojik uygulamalar, araştırmalar, risk yönetim metotları ve risk analiz metotları güncel bir şekilde takip edilmeli, teknolojik gelişmeler için gerekli İş Sağlığı ve Güvenliği yapılanmaları tasarlanmalı, çalşsanlarda ve işverenlerde gerekli bilinci oluşturmak için kurumsal olarak sistematik bir anlayış kazanılması gerekmektedir.

\section{KAYNAKLAR}

[1] Yokel, R. A., \& MacPhail, R. C. (2011). Engineered nanomaterials: exposures, hazards, and risk prevention. Journal of Occupational Medicine and Toxico$\log y, 6: 7$
[2] National Nanotechnology Initiative. (2011). Strategic Plan. National Science and Technology Council, Committee of Technology, Subcommittee on Nanoscale Science, Engineering, and Technology. p.3 [https://www.nano.gov/sites/default/files/ pub_resource/2011_strategic_plan.pdf]

[3] Jahnel, J., Fleischer, T., \& Seitz, S. B. (2013). Risk assessment of nanomaterials and nanoproductsadaptation of traditional approaches. In Journal of Physics: Conference Series (Vol. 429, No. 1, p. 012063). IOP Publishing. Organic Consumers Association: Groups demand EPA stop sale of 200+ potentially dangerous nano-silver products.1195. [http://www.organicconsumers.org/articles/ article_11955.cfm]

[4] Group files legalcction for EPA to stop sale of 200 +Nanosilver products, assessment, N. H. nano. 2008 p.6 [https://www.nanowerk.com/nanorisk/pdf/ nanoRISK_vol3_iss3.pdf]

[5] Kagan, V. E., Shi, J., Feng, W., Shvedova, A. A., \& Fadeel, B. (2010). Fantastic voyage and opportunities of engineered nanomaterials: What are the potential risks of occupational exposures? Journal of occupational and environmental medicine, 52(9), 943-946.

[6] OECD. List of manufactured nanomaterials and list of endpoints for phase one of the OECD testing programme. OECD Environment, Health and Safety Publications Series on the safety of manufactured nanomaterials No 6. Document ENV/JM/MONO (2008)13. Organization for Economic Coordination and Development. Paris, France; 2008a

[7] SCoEaNIHR, E. S. (2009). Risk Assessment of Products of Nanotechnologies. European Commission, Scientific Committee on Emerging and Newly Identified Health Risks (SCENHR): Brussels, Belgium. [http:// ec.europa.eu/health/ph_risk/committees/04_scenihr/ docs/scenihr_o_023.pdf]

[8] Hansen, S. F., Howard, C. V., Martuzzi, M., \& Depledge, M. (2013). Nanotechnology and human health: Scientific evidence and risk governance: Report of the WHO expert meeting 10-11 December 2012, Bonn, Germany. [http://www.euro.who.int/_data/ assets/pdf_file/0018/233154/e96927.pdf?ua=1]

[9] Tsuji, J. S., Maynard, A. D., Howard, P. C., James, J. T., Lam, C. W., Warheit, D. B., \& Santamaria, A. B. (2005). Research strategies for safety evaluation of nanomaterials, part IV: risk assessment of nanoparticles. Toxicological sciences, 89(1), 42-50.

[10] Development of a web based REACH Toolkit to support the chemical safety assessment of nanomate- 
rials, Guidance on available methods for risk assessment of nanomaterials, Technical Guidances series 2015

[11] Zuin, S., Micheletti, C., Critto, A., Pojana, G., Johnston, H., Stone, V., ... \& Marcomini, A. (2011). Weight of evidence approach for the relative hazard ranking of nanomaterials. Nanotoxicology, 5(3), 445458.

[12] Olson, M. S., \& Gurian, P. L. (2012). Risk assessment strategies as nanomaterials transition into commercial applications. Journal of Nanoparticle Research, 14(4), 786.

[13] Scientific Committee on Emerging and Newly Identified Health Risks. (2012). Opinion on the Memorandum on the use of the scientific literature for human health risk assessment purposes - weighing of evidence and expression of uncertainty.

[14] Scientific Committee on Emerging and Newly Identified Health Risks. (2007). Opinion on the appropriateness of the Risk Assessment Methodology in accordance with the technical guidance documents for new and existing substances for assessing the risks of nanomaterials. [http://ec.europa.eu/health/ ph_risk/committees/04_scenihr/docs/ scenihr_o_010.pdf]

[15] EFSA Scientific Committee. (2011). Guidance on the risk assessment of the application of nanoscience and nanotechnologies in the food and feed chain. EFSA Journal, 9(5), 2140.

[16] Grieger, K. D., Laurent, A., Miseljic, M., Christensen, F., Baun, A., \& Olsen, S. I. (2012). Analysis of current research addressing complementary use of life -cycle assessment and risk assessment for engineered nanomaterials: Have lessons been learned from previous experience with chemicals? Journal of Nanoparticle Research, 14(7), 958.

[17] Tervonen, T., Linkov, I., Figueira, J. R., Steevens, J., Chappell, M., \& Merad, M. (2009). Risk-based classification system of nanomaterials. Journal of Nanoparticle Research, 11(4), 757-766.

[18] Warheit, D. B., Webb, T. R., \& Reed, K. L. (2003, March). Pulmonary toxicity studies with $\mathrm{TiO} 2$ particles containing various commercial coatings. Toxicologist. Volume 72, Issue 1, Pages 298A

[19] Unit, R. A. (2004). Nanotechnologies: a preliminary risk analysis on the basis of a Workshop Organized in Brussels on 1-2 March 2004 by the Health and Consumer Protection Directorate General of the European Commission. [http://ec.europa.eu/health/ ph_risk/documents/ev_20040301_en.pdf]
[20] Arvidsson, R., Furberg, A., \& Molander, S. (2016). Review of Screening Risk Assessment Methods for Nanomaterials. Chalmers University of Technology.

[21] Geraci, C. L., Lentz, T., \& Niemeier, R. (2009). Qualitative risk characterization and management of occupational hazards: control banding (CB); a literature review and critical analysis.

[22] Burgman, M. (2005). Risks and decisions for conservation and environmental management. Cambridge University Press.

[23] Exposure to Engineered Nanomaterials and Occupational Health and Safety Effects, October 2011 INAIL, Department of Occupational Medicine

[24] Vervoort, M. B. H. J. (2012). Risk assessment of occupational used nanomaterials: A comparison of risk assessment methods in order to determine the risk of occupational used nanomaterials in a research environment (Doctoral dissertation, 8 esis. Netherland School of Public and Occupational Health).

[25] Jensen, K. A., Saber, A. T., Kristensen, H. V., Liguori, B., Jensen, A. Ø., Koponen, I. K., \& Wallin, H. (2014). NanoSafer vs. 1.1 Nanomaterial risk assessment using first order modeling. In Topical Scientific Workshop on Regulatory Challenges in Risk Assessment of Nanomaterials.

[26] Fleury, D., Fayet, G., Vignes, A., Henry, F., \& Frejafon, E. (2013, May). Nanomaterials risk assessment in the process industries: evaluation and application of current control banding methods. In 14. International Symposium on Loss Prevention and Safety Promotion in the Process Industry (Vol. 31, pp. 949-954). AIDIC. Milano.

[27] Silva, F., Sousa, S. P. B., Arezes, P., Swuste, P., Ribeiro, M. C. S., \& Baptista, J. S. (2015). Qualitative risk assessment during polymer mortar test specimens preparation-methods comparison. In Journal of Physics: Conference Series (Vol. 617, No. 1, p. 012037). IOP Publishing.

[28] Occupational Safety and Health Administration. (2013). OSHA Fact Sheet: Working Safely with Nanomaterials. Occupational Safety and Health Administration. [https://www.osha.gov/Publications/ OSHA_FS-3634.pdf]

[29] Eastlake, A., Hodson, L., Geraci, C., \& Crawford, C. (2012). A critical evaluation of material safety data sheets (MSDSs) for engineered nanomaterials. Journal of Chemical Health and Safety, 19(5), 1-8. 